\title{
COMPARISON BETWEEN THE INFLUENCE OF IMPLANT DIAMETER AND IMPLANT LENGTH ON THE PRIMARY STABILITY
}

\author{
Elitsa Sabeva \\ Department of Periodontology and Dental Implantology, \\ Faculty of Dental Medicine, Medical University of Varna
}

\begin{abstract}
INTRODUCTION: The primary stability is a factor for successful osseointegration of dental implants. It is believed that factors that can increase the contact area between the implant and the bone, such as the implant shape, length, and diameter, can also increase the primary stability.

AIM: The aim of this study was to determine whether the increase of implant length or the increase of implant diameter would contribute more to the enhancement of primary stability.

MATERIALS AND METHODS: The implant primary stability of 60 implants distributed in 6 groups, according their diameter, length and surface topography was evaluated using three methods: assessment of mean insertion torque, periotest values, and resonance frequency analysis.

RESULTS AND DISCUSSION: The results demonstrated that the primary stability achieved by increasing the diameter of the implants by $0.7 \mathrm{~mm}$ was comparable to that obtained by increasing their length by 2 $\mathrm{mm}$ at a smaller diameter $(4.1 \mathrm{~mm})$. When the difference in the diameter increased more (from $0.7 \mathrm{~mm}$ to $1.5 \mathrm{~mm}$, when comparing the $3.3 \mathrm{~mm} / 10 \mathrm{~mm}$ and $4.8 \mathrm{~mm} / 8 \mathrm{~mm}$ implants), the increase of the length of the smaller diameter implants did not result in primary stability values comparable to those obtained during the insertion of wider and shorter implants.

CONCLUSION: Considering our results as well as the literature data, we can conclude that the increase of the implant diameter affects more the improving of the primary stability than the increase of the implant length. However, it should be taken into account that this refers to a specific diameter change of $1.5 \mathrm{~mm}$ and length change of $2 \mathrm{~mm}$. More studies, including implants with a greater difference in the length and a different diameter to length ratio, are needed to confirm or reject this relation.
\end{abstract}

Keywords: diameter, length, implant, primary stability

Address for correspondence:

Elitsa Sabeva

Faculty of Dental Medicine

Medical University of Varna

84 Tsar Osvoboditel Blvd

9000 Varna

e-mail: Elitsa.Sabeva@mu-varna.bg

Received: November 3, 2018

Accepted: December 18, 2018

\section{INTRODUCTION}

Implant primary stability is defined as the biometric stability of the implant immediately after its insertion into the bone. Primary stability develops into secondary stability as healing, integration and biological changes in the bone-implant interface progress (1). The primary stability is a factor for successful osseointegration of dental implants $(2,3,4)$. 
Primary stability is a result of a frictional interaction between the implant and the bone. Less influence has the wedging of elements of the implant design in the bone as a consequence of elastic deformation $(5,6)$. The simplicity that describes this phenomenon is: $\mathrm{F}=\mathrm{k}$. N, where $\mathrm{F}$ is the friction force, $\mathrm{k}$ - the coefficient of friction (specific for each surface) and $\mathrm{N}$ is the pressure between two surfaces (7).

One of the main factors with regard to primary stability is the bone-to-implant contact $(8,9,10)$.

It is believed that factors that can increase the contact area between the implant and the bone, such as the implant shape, length, and diameter, can also increase the primary stability, as it should be taken into account that the characteristics of the implant bone bed can also play a key role in the formation of the bone-to-implant contact $(11,12)$.

The shape, length and diameter of the implant, as well as the geometry of its thread, describe the implant macrodesign (13).

According to Langer et al. (14) the large diameter implants are created to increase the bone-titan surface contact. Peev et al. (15) concluded that the resonance frequency analysis (RFA) method could be useful for prevention of implant failure by tracing the changes in the implant stability. Ostmann et al. (16), investigating the implant primary stability by resonance frequency analysis, observed higher implant stability quotient (ISQ) values in implants with a wider platform, whereas according to others $(17,18,19)$, the diameter of the implant had no significant influence on these values, respectively on the primary stability. Lachmann et al. (11) examined the primary stability of implants using the both parameters: periotest values (PTV) and ISQ, and found that there was a correlation between the implant diameter and the primary stability, adding that with a diameter increase of more than $4 \mathrm{~mm}$, no significant differences in the values were observed. Other authors $(20,21)$ also support the view that the larger diameter corresponds to greater primary stability.

Tsolaki et al. (22) compared the values obtained during RFA and insertion torque (IT) measurements of $10 \mathrm{~mm}$ and $13 \mathrm{~mm}$ long implants, as they observed significantly higher values using longer implants. They concluded that implant length has a positive effect on the primary stability, as the primary stability could be improved by increasing the implant length. Other authors also came to similar conclusion (23).

Merheb et al. (17) obtained the following results: implant length did not significantly affect the mean results of RFA. In a study about the implant stability in patients suffering from osteoporosis, the author came to the same conclusion: the length of implants did not significantly affect their stability according to the ISQ values (24).

\section{AIM}

The aim of this study was to determine whether the increase of implant length or the increase of implant diameter would contribute more to the enhancement of primary stability.

\section{MATERIALS AND METHODS}

Sixty Tissue Level implants were placed into 60 artificial bone blocks with a corticocancellous structure. Twenty of them were $10 \mathrm{~mm}$ long, with a diameter of $3.3 \mathrm{~mm}$ and thread pitch of $1.0 \mathrm{~mm}, 20 \mathrm{im}$ plants were with a length of $10 \mathrm{~mm}$, diameter of 4.1 $\mathrm{mm}$ and thread pitch of $1.25 \mathrm{~mm}$, and the last twenty were $8 \mathrm{~mm}$ long, with a diameter of $4.8 \mathrm{~mm}$ and thread pitch of $1.25 \mathrm{~mm}$. The surface of half of the implants in each group was smooth and the surface of the rest of the implants - rough. The rough surface was achieved by sandblasting with a large grit of $\mathrm{Al}_{2} \mathrm{O}_{3}$ followed by acid etching.

During the implant placement were assessed the maximum insertion torque (MIT) using iChiropro (Bien Air Dental SA, Bienne, Switzerland), the damping capacity using Periotest Classic (Medizintechnik Gulden, Germany). RFA was done using Osstell Mentor device (Göteborg, Sweden). During the osteotomy, the implant insertion and the assessments, the artificial bone blocks were kept stable using vise.

Site preparation was performed. First the position of the osteotomy was marked with a $1.4 \mathrm{~mm}$ round bur, whereafter the mark was expanded with a $2.3 \mathrm{~mm}$ round bur. Pilot osteotomy was made using $2.2 \mathrm{~mm}$ pilot drill to $10 \mathrm{~mm}$ (for the $3.3 \mathrm{~mm}$ and 4.1 $\mathrm{mm}$ diameter implants) and to $8 \mathrm{~mm}$ (for the $4.8 \mathrm{~mm}$ diameter implants) depth. Then the osteotomy was enlarged to the desired diameter with a $2.8 \mathrm{~mm}$ drill for the 3.3 diameter implants, then with a $3.5 \mathrm{~mm}$ 
drill for the implants with a diameter of $4.1 \mathrm{~mm}$, and with $4.2 \mathrm{~mm}$ drill for the wider $(4.8 \mathrm{~mm})$ implants.

The marginal area of the osteotomy was enlarged with a profile drill with a corresponding diameter. During the implant site preparation continuous cooling with sterile saline solution was performed.

The implants were placed using contra-angle handpiece CA 20:1 L Micro-series (Bien Air).

The insertion torque was monitored and assessed using the implant unit iChiropro (Bien Air Dental SA, Bienne, Switzerland) and its torque function. The implants were placed into the artificial bone blocks with controlled speed of $15 \mathrm{rpm}$, as the insertion finished, the software of the device calculated the maximum insertion torque (MIT).

The damping capacity was measured using Periotest Classic device according to the following protocol: the transfer part of the implants was used as a suprastucture. The assessments were done, as the position of the handpiece of the device was perpendicular to the axis of the transfer, $4 \mathrm{~mm}$ above the crestal bone. The results were presented as PTV.

The performance of RFA was done using Osstell Mentor device. The corresponding Smartpeg el- ement was installed on the platform of the implants. The position of the probe of the device was perpendicular to the Smartpeg element's axis, as the probe was held at the level of its magnet. The measurements were done in two directions, perpendicular to each other and the mean value of both measurements was registered. The results were presented as ISQ values.

The results were analyzed using IBM SPSS Statistics 19 software.

\section{RESULTS}

The mean MIT, PTV and ISQ values for the 6 groups of implants are presented in Table 1.

To determine which element of the implant macrodesign (the length or the diameter) influences the implant primary stability more, we compared the mean MIT, PTV and ISQ values, obtained during the insertion of implants with a diameter of $4.1 \mathrm{~mm}$ and a length of $10 \mathrm{~mm}$, and a diameter of $4.8 \mathrm{~mm}$ and a length of $8 \mathrm{~mm}$.

With an implant diameter increase by $0.7 \mathrm{~mm}$ and length decrease by $2 \mathrm{~mm}$ only the maximum insertion torque demonstrated significant difference, as it is greater for the shorter smooth and rough implants of larger diameter. The resonance frequency

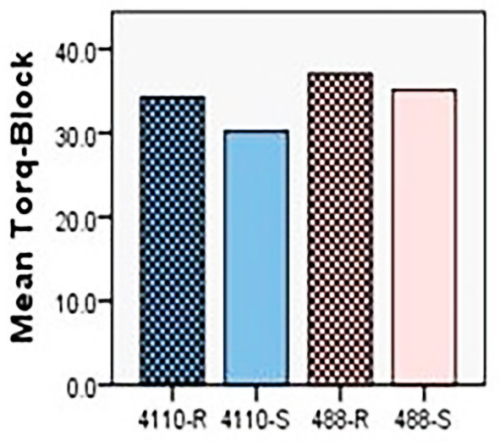

Type/dimensions
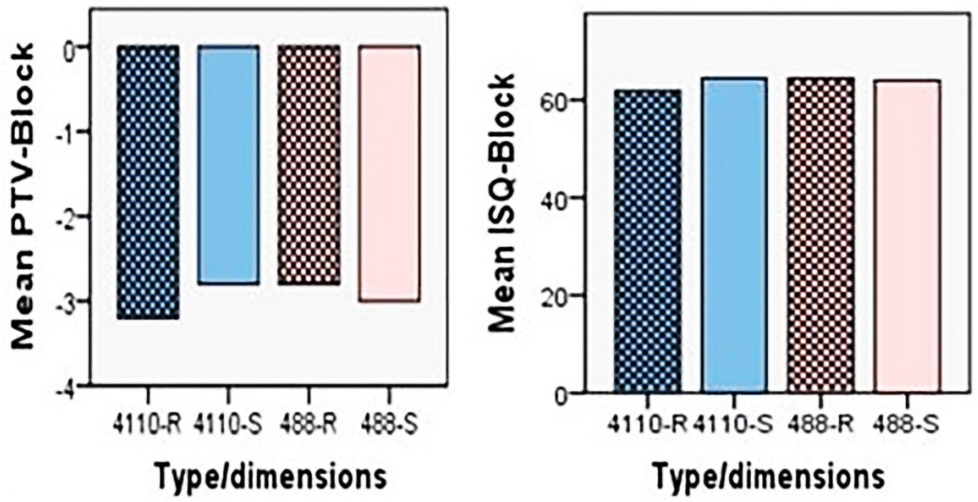

Fig. 1. The mean MIT, PTV and ISQ of $4.1 \mathrm{~mm} / 10 \mathrm{~mm}$ (4110) and $4.8 \mathrm{~mm} / 8 \mathrm{~mm}$ (488) implants with rough (-R) and smooth (-S) surface

Table 1. The mean MIT, PTV and ISQ for the different implant groups

\begin{tabular}{l|c|c|c|c|c|c|}
\multirow{2}{*}{ Dimension } & \multicolumn{3}{|c|}{ Smooth Surface } & \multicolumn{3}{c}{ Rough Surface } \\
\cline { 2 - 5 } & MIT & PTV & ISQ & MIT & PTV & ISQ \\
$3.3 \mathrm{~mm} / 10 \mathrm{~mm}$ & 14.630 & 1.3 & 59 & 15.300 & 1.1 & 59.1 \\
$4.8 \mathrm{~mm} / 8 \mathrm{~mm}$ & 35.100 & -3 & 64 & 37.040 & -2.8 & 64.4 \\
$4.1 \mathrm{~mm} / 10 \mathrm{~mm}$ & 30.200 & -2.8 & 64.5 & 34.270 & -3.2 & 61.9 \\
\hline
\end{tabular}


analysis and the damping capacity did not indicate significant difference in the primary stability of both sizes of implants (Fig. 1).

When there was an increase in the diameter of $1.5 \mathrm{~mm}$ and decrease in the length of $2 \mathrm{~mm}$, significant difference in the primary stability of the $3.3 \mathrm{~mm} / 10 \mathrm{~mm}$ and of the $4.8 \mathrm{~mm} / 8 \mathrm{~mm}$ implants was observed, considering the results of all three assessment methods. The maximum insertion torque, PTV and the ISQ values were higher for the implants with a diameter of $4.8 \mathrm{~mm}$ and a length of $8 \mathrm{~mm}$. Less demonstrative were the results obtained during the resonance frequency analysis, while the other two methods showed significant difference (Fig. 2). This dependence was observed for both surface modifications of the implants. ry stability values comparable to those obtained during the insertion of wider and shorter implants. Other studies support the view that the implant length has less influence on the primary stability than the implant diameter $(20,26,21)$. The authors also add that the primary stability achieved by increasing the length is not comparable to that obtained by increasing the density of the artificial bone blocks (26). According to our results, implants with a diameter of 3.3 $\mathrm{mm}$ demonstrated significantly lower primary stability, despite their longer length and smaller thread pitch, which, according to the most authors, leads to improved primary stability $(8,27)$. The literature data on the impact of the implant length on primary stability are contradictory. According to some authors, the implant length either does not affect $(28,29)$, or
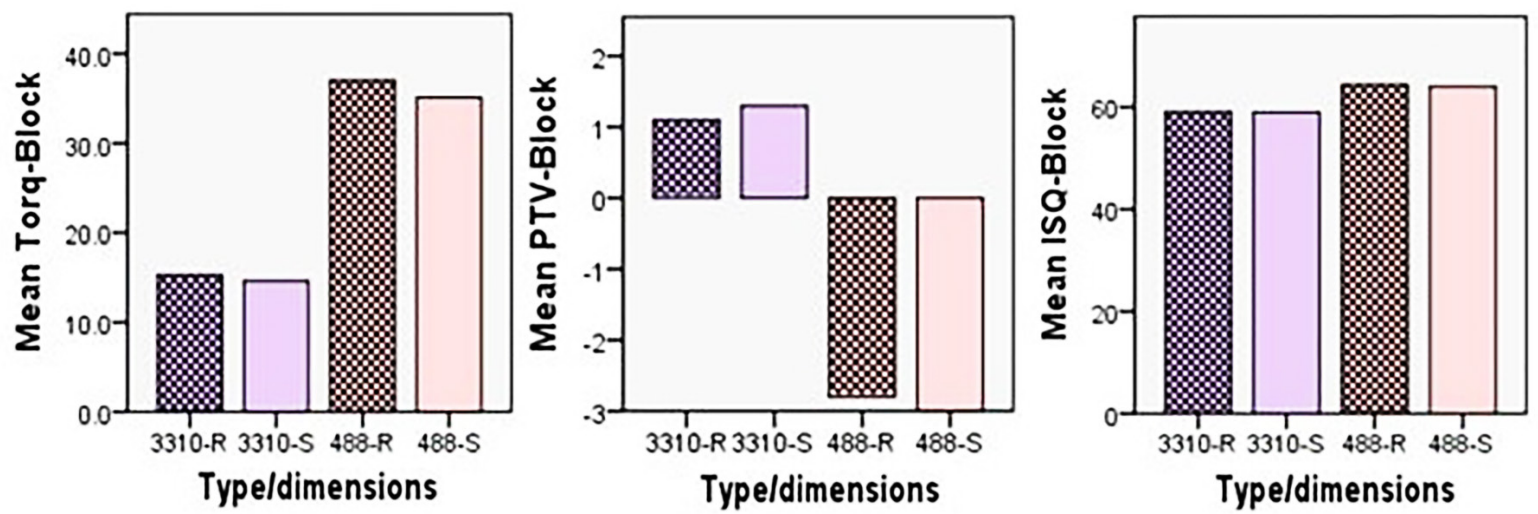

Fig. 2. The mean MIT, PTV and ISQ of $3.3 \mathrm{~mm} / 10 \mathrm{~mm}$ (3310) and $4.8 \mathrm{~mm} / 8 \mathrm{~mm}$ (488) implants with rough (-R) and smooth (-S) surface

\section{DISCUSSION}

RFA, damping capacity and MIT seemed to be reliable for measuring implant primary stability. The alteration of the implant parameters resulted in alteration of the implant stability, which can be detected by the methods mentioned above. Same relation was established also in previous study, conducted under similar conditions (25).The results demonstrated that the primary stability achieved by increasing the diameter of the implants by $0.7 \mathrm{~mm}$ is comparable to that obtained by increasing their length by $2 \mathrm{~mm}$ at a smaller diameter $(4.1 \mathrm{~mm})$. When the difference in the diameter increased more (from $0.7 \mathrm{~mm}$ to 1.5 $\mathrm{mm}$, when comparing the $3.3 \mathrm{~mm} / 10 \mathrm{~mm}$ and 4.8 $\mathrm{mm} / 8 \mathrm{~mm}$ implants), the increase of the length of the smaller diameter implants did not result in prima- even has a weakly negative impact on the primary stability $(30,16)$. Other studies prove the opposite: primary stability could be increased when longer implants were placed $(22,23)$. According to our study, there was no significant difference in the primary stability of the implants with a $0.7 \mathrm{~mm}$ larger diameter and the $2 \mathrm{~mm}$ longer implants with smaller diameter. Gomez-Polo (31) et al. reported similar results. They compared implants with the same diameter and $1.5 \mathrm{~mm}$ difference in implant length. Despite the controversial reports about the effect of the implant length on the primary stability, most of the literature data suggests that the larger implant diameter improves the implant primary stability $(14,16,32)$, provided that this depends on how much exactly the diameter increases $(11,33)$. 


\section{CONCLUSION}

Considering our results as well as the literature data, we can conclude that the increase of the implant diameter affects the improving of the primary stability more than the increase of the implant length. However, it should be taken into account that this refers to a specific diameter change of $1.5 \mathrm{~mm}$ and length change of $2 \mathrm{~mm}$. More studies, including implants with a greater difference in the length and a different diameter to length ratio, are needed to confirm or reject this relation.

\section{REFERENCES}

1. Meredith N, Alleyne D, Cawley P. Quantitative determination of the stability of the implant-tissue interface using resonance frequency analysis. Clin Oral Implants Res. 1996;7(3):261-7.

2. Javed F, Romanos GE. The role of primary stability for successful immediate loading of dental implants. A literature review. J Dent. 2010;38(8):61220. doi: 10.1016/j.jdent.2010.05.013.

3. Lioubavina-Hack N, Lang NP, Karring T. Significance of primary stability for osseointegration of dental implants. Clin Oral Implants Res. 2006;17(3):244-50. doi: 10.1111/j.1600-0501.2005.01201.x.

4. Meredith N. Assessment of implant stability as a prognostic determinant. Int J Prosthodont. 1998;11(5):491-501.

5. Deporter DA, Watson PA, Pilliar RM, Melcher AH, Winslow J, Howley TP, et al. A histological assessment of the initial healing response adjacent to porous-surfaced, titanium alloy dental implants in dogs. J Dent Res. 1986 Aug;65(8):1064-70. doi: $10.1177 / 00220345860650080501$.

6. Pilliar RM, Simmons CA. Mechanical factors and osseointegration: influence of implant design. In: Zarb G, Lekholm U, Albrektsson T, Tennenbaum $\mathrm{H}$, editors. Aging, osteoporosis, and dental implants. Chicago, IL: Quintessence; 2002. pp. 35-44.

7. Joos G, Freeman IM. Theoretical Physics. Dover Publications;1987. pp. 50-1.

8. Orsini E, Giavaresi G, Trirè A, Ottani V, Salgarello S. Dental implant thread pitch and its influence on the osseointegration process: an in vivo comparison study. Int J Oral Maxillofac Implants. 2012;27(2):383-92.

9. Winter W, Möhrle S, Holst S, Karl M. Parameters of implant stability measurements based on reso- nance frequency and damping capacity: a comparative finite element analysis. Int J Oral Maxillofac Implants. 2010;25(3):532-9.

10. Ryu HS, Namgung C, Lee JH, Lim YJ. The influence of thread geometry on implant osseointegration under immediate loading: a literature review. J Adv Prosthodont. 2014;6(6):547-54. doi: 10.4047/ jap.2014.6.6.547.

11. Lachmann S, Laval JY, Axmann D, Weber H. Influence of implant geometry on primary insertion stability and simulated peri-implant bone loss: an in vitro study using resonance frequency analysis and damping capacity assessment. Int J Oral Maxillofac Implants. 2011;26(2):347-55.

12. Barikani $H$, Rashtak $S$, Akbari S, Fard MK, Rokn A. The effect of shape, length and diameter of implants on primary stability based on resonance frequency analysis. Dent Res J (Isfahan). 2014;11(1):87-91.

13. Abuhussein H, Pagni G, Rebaudi A, Wang HL. The effect of thread pattern upon implant osseointegration. Clin Oral Implants Res. 2010;21(2):129-136. doi: 10.1111/j.1600-0501.2009.01800.x.

14. Langer B, Langer L, Herrmann I, Jorneus L. The wide fixture: a solution for special bone situations and a rescue for the compromised implant. Part 1. Int J Oral Maxillofac Implants. 1993;8(4):400-8.

15. Peev S, Atanasov D. Platelet-rich plasma - an accelerator of the secondary stability of immediate loaded implants. J of IMAB - Annual Proceeding (Scientific Papers). 2007;2:38-40.

16. Ostman PO, Hellman M, Wendelhag I, Sennerby L. Resonance frequency analysis measurements of implants at placement surgery. Int J Prosthodont. 2006;19(1):77-83; discussion 84.

17. Merheb J, Van Assche N, Coucke W, Jacobs R, Naert I, Quirynen M. Relationship between cortical bone thickness or computerized tomography-derived bone density values and implant stability. Clin Oral Impl Res. 2010; 21(6):612-7. doi: 10.1111/j.1600-0501.2009.01880.x.

18. Han J, Lulic M, Lang NP. Factors influencing resonance frequency analysis assessed by Osstell mentor during implant tissue integration: II. Implant surface modifications and implant diameter. Clin Oral Implants Res. 2010;21(6):605-11. doi: 10.1111/j.1600-0501.2009.01909.x.

19. Bilhan H, Geckili O, Mumcu E, Bozdag E, Sünbüloğlu E, Kutay O. Influence of sur- 
gical technique, implant shape and diameter on the primary stability in cancellous bone. J Oral Rehabil. 2010;37(12):900-7. doi: 10.1111/j.1365-2842.2010.02117.x.

20. Maiorana C, Farronato D, Pieroni S, Cicciu $\mathrm{M}$, Andreoni D, Santoro F. A four-year survival rate multicenter prospective clinical study on 377 implants: Correlations between implant insertion torque, diameter, and bone quality. J Oral Implantol. 2015;41(3):e60-5. doi: 10.1563/ AAID-JOI-D-13-00206.

21. Rokn A, Ghahroudi AR, Mesgarzadeh A, Miremadi A, Yaghoobi S. Evaluation of stability changes in tapered and parallel wall implants: A human clinical trial. J Dent (Tehran) 2011;8(4):186-200.

22. Tsolaki IN, Tonsekar PP, Najafi B, Drew HJ, Sullivan $\mathrm{AJ}$, Petrov SD. Comparison of osteotome and conventional drilling techniques for primary implant stability: An in vitro study. J Oral Implantol. 2016;42(4):321-5. doi: 10.1563/aaid-joi-D-15-00176.

23. Möhlhenrich SC, Kniha K, Heussen N, Hölzle F, Modabber A. Effects on primary stability of three different techniques for implant site preparation in synthetic bone models of different densities.

Br J Oral Maxillofac Surg. 2016;54(9):980-6. doi: 10.1016/j.bjoms.2016.07.004.

24. Merheb J, Temmerman A, Rasmusson L, Kübler A, Thor A, Quirynen M. Influence of skeletal and local bone density on dental implant stability in patients with osteoporosis. Clin Implant Dent Relat Res. 2016;18(2):253-60. doi: 10.1111/cid.12290.

25. Sabeva E, Peev S, Miteva M, Georgieva M. The impact of the thread design compared to the impact of the surface topography on the primary stability of implants inserted into fresh pig ribs. Scr Sci Medicinae Dentalis. 2017; 3(1):60-4. doi: 10.14748/ ssmd.v3i1.2917.

26. Möhlhenrich SC, Heussen N, Elvers D, Steiner T, Hölzle F, Modabber A. Compensating for poor primary implant stability in different bone densities by varying implant geometry: a laboratory study. Int J Oral Maxillofac Surg. 2015;44(12):1514-20. doi: 10.1016/j.ijom.2015.08.985.
27. Lan TH, Du JK, Pan CY, Lee HE, Chung WH. Biomechanical analysis of alveolar bone stress around implants with different thread designs and pitches in the mandibular molar area. Clin Oral Investig. 2012;16(2):363-9. doi: 10.1007/s00784-011-0517-z.

28. Calvo-Guirado JL, López Torres JA, Dard M, Javed F, Pérez-Albacete Martínez C, Maté Sánchez de Val JE. Evaluation of extrashort 4-mm implants in mandibular edentulous patients with reduced bone height in comparison with standard implants: a 12-month results. Clin Oral Implants Res. 2016;27(7):867-74. doi: 10.1111/clr.12704.

29. de Oliveira GJ, Barros-Filho LA, Barros LA, Queiroz TP, Marcantonio E Jr. In vitro evaluation of the primary stability of short and conventional implants. J Oral Implantol. 2016;42(6):458-63. doi: 10.1563/aaid-joi-D-16-00094.

30. Miyamoto I, Tsuboi Y, Wada E, Suwa H, Iizuka T. Influence of cortical bone thickness and implant length on implant stability at the time of surgery-clinical, prospective, biomechanical, and imaging study. Bone. 2005;37(6):776-80. doi: 10.1016/j. bone.2005.06.019.

31. Gómez-Polo M, Ortega R, Gómez-Polo C, Martín C, Celemín A, Del Río J. Does length, diameter, or bone quality affect primary and secondary stability in self-tapping dental implants? J Oral Maxillofac Surg. 2016;74(7):1344-53. doi: 10.1016/j. joms.2016.03.011

32. Horwitz J, Zuabi O, Peled M. Resonance frequency analysis in immediate loading of dental implants. Refuat Hapeh Vehashinayim. 2003;20(3):80-8, 104.

33. Engelke W, Decco OA, Cura AC, Maldonado I, Crippa FG. Influence of implant diameter in the displacement of dental implants in trabecular bovine bone under a static lateral load: experimental results and computational modeling. Implant Dent. 2014;23(6):635-40. doi: 10.1097/ ID.0000000000000169. 